\title{
Difficult conversations
}

\section{Opinion}

A treatment with a patient is a difficult process, with individual approach to each patient, taking into account his/her desires, possibilities and needs, attitudes and beliefs. Assessing the physical, mental, social and spiritual condition and common planning of care are a reflection of further quality of life and dignified death. Pain relieving and other symptoms such as: nausea and vomiting, constipation, diarrhea, dyspnoea, restlessness and distress (that causes suffering) and adequate care, is the crucial task for person taking cares for palliative patients. ${ }^{1}$

In the morning, around 10h, a patient's (B.D.) wife phoneedand asked for advice and help for the pain her husband suffering (VAS up to 10 with intensity oscillations). Patient was diagnosed with C71.9Malignant brain disorder, no analgesics so far recommended, family doctor advised Medrol increase medication, and no further instructions received. During a conversation with her husband, a home visit was arranged to provide a complete insight into the patient's condition, needs assessment and counseling for the best possible patient care and pain relief therapy.

By reviewing the documentation and communicating with the patient, it becomes clear that the patient is disoriented in all three directions, recognizing his wife at times. Carrying diapers, dependent on someone else's help in all their personal needs (feeding, maintaining personal hygiene, dressing, and the wife states that heteroanamnesticly husband"s situation is getting worse day by day.) Until few days ago was able to walk a while with a help but now is not able to stand up from a bed). The wife is fragile, looks exhausted, two years ago her son was killed and before this tragic event she had nursed her mother for 10 years with Alzheimer's diagnosis. She lives alone with her husband, has modest income, a son who lives separately, not able to take care of her father (his wife is suffering from breast cancer, he is the only one working and providing for his family). A Mobile
Volume 2 Issue 3 - 2018

\author{
Kata Ivanišević, Anđa Ledić \\ Master of nursing, University Hospital Centre Rijeka, Croatia
}

Correspondence: Kata Ivanišević, Anđa Ledić, University Hospital Centre Rijeka, Kresimirova 42, 51000 Rijeka, Croatia, Email k.ivanise@gmail.com

Received: April 17, 2018 | Published: May 01, 2018

Palliative Team has been organized, making home visit on the very same day, providing analgesics, reducing the patient's pain.

Talked with patient's wife about further expected changes in B.D., about all forms of care, and came to the conclusion that the best solution forall of them will be hospice accommodation. 22/08/2017., the wife phoned that B.D. was put in Hospice, where he lived without pain, with the best possible palliative care and died two weeks later. The wife of the deceased lives alone, struggling with the losses of the closest family members and is involved in psychosocial support during the process of greaving.

\section{Acknowledgements}

None.

\section{Conflict of interest}

The author declares no conflict of interest.

\section{References}

1. James A. Abeceda of palliative care, the script. 2nd edn. p. $57-60$. 